\title{
Quality assessment of the essential oil from Eucalyptus globulus Labill of Blida (Algeria) origin
}

\author{
Mohamed Nadjib Boukhatem ${ }^{1, *}$, Ferhat Mohamed Amine ${ }^{2}$, Abdelkrim Kameli $^{3}$, \\ Fairouz Saidi ${ }^{1}$, Kerkadi Walid ${ }^{1}$, Sadok Bouziane Mohamed ${ }^{1}$ \\ ${ }^{1}$ Laboratoire de Biotechnologies Végétales, Département de Biologie et Physiologie Cellulaire, \\ Faculté des Sciences de la Nature et de la Vie, Université Blida 1, Blida, Algeria \\ *Tel: +213559146610 \\ ${ }^{2}$ Laboratoire de Recherche sur les Produits Bioactifs et Valorisation de la Biomasse, \\ Département de Chimie, Ecole Normale Supérieure de Kouba, Algiers, Algeria \\ ${ }^{3}$ Laboratoire Eco-Physiologie Végétale, Département des Sciences Naturelles, \\ Ecole Normale Supérieure de Kouba, Algiers, Algeria \\ *E-mail address: mn.boukhatem@yahoo.fr
}

\begin{abstract}
Despite the reputation earned by aromatic and medicinal plants of Algeria, the chemical constituents of Eucalyptus globulus essential oil (EGEO) of Blida origin has not previously been investigated. Thus, the present study has been conducted for the determination of chemical constituents and different physico-chemical properties of the EGEO. Chemical composition of the EGEO, grown in Algeria, was analysed by Gas Chromatography-Mass Spectrometry. The chemical components were identified on the basis of Retention Time and comparing with mass spectral database of standard compounds. Relative amounts of detected compounds were calculated on the basis of GC peak areas. Fresh leaves of E. globulus on steam distillation yielded $0.96 \%(\mathrm{v} / \mathrm{w})$ of essential oil whereas the analysis resulted in the identification of a total of 11 constituents, 1.8 cineole $(85.8 \%), \alpha$ pinene $(7.2 \%)$, and $\beta$-myrcene $(1.5 \%)$ being the main components. Other notable compounds identified in the oil were $\beta$-pinene, limonene, $\alpha$-phellandrene, $\gamma$-terpinene, linalool, pinocarveol, terpinen-4-ol, and $\alpha$-terpineol. The physical properties such as specific gravity, refractive index and optical rotation and the chemical properties such as saponification value, acid number and iodine number of the EGEO were examined. The oil extracted has been analyzed to have $1.4602-1.4623$ refractive index value, $0.918-0.919$ specific gravity (sp.gr.), $+9-+10$ optical rotation that satisfy the standards stipulated by European Pharmacopeia. All the physical and chemical parameters were in the range indicated by the ISO standards. Our findings will help to access the quality of the Eucalyptus oil which is important in the production of high value essential oils that will help to improve the economic condition of the community as well as the nation.
\end{abstract}

Keywords: Eucalyptus globulus Labill; Chemical composition; Essential oil; Gas Chromatography; Eucalyptol

\section{INTRODUCTION}

Plant essential oils (EO) are obtained from non-woody parts of the plant, particularly foliage, through steam or hydrodistillation. From a modern point of view, they are produced 
from natural raw materials by a number of possible extraction processes. The basic components of EO are hydrocarbons, aromatic derivatives, terpenes and their oxygenated derivatives (mono- and sesqui-terpenoids, alcohols and esters) [1,2]. Aromatic plants and their volatile oils have been used since antiquity in fragrances and flavor, as spice or condiment, in alternative and complementary medicine, as antibacterial-antifungal agents, and to repel insect or protect stored products $[3,4]$.

The use of EO as functional ingredients in drinks, foods, cosmetics and toiletries is gaining momentum, both for the growing consumers' interest in the ingredients coming from natural products, and also because of the increasing concern with harmful synthetic chemical additives [5,6]. Due to their bioactive chemical compounds, volatile oils are certainly promising in view of their use as efficient antimicrobial and therapeutic agents. With the rising significance in the use of EO in both food and pharmaceutical industries, a systematic assessment of the phytochemical extracts has become increasingly essential $[2,7,8]$. Further, EO quality is determined by a complex of agrobiological and technological factors, weather and geographical conditions of cultivation, duration of storage $\&$ the conditions thereof. There are some conventional ways of EO extraction to produce natural flavour products. The chemotype of the armatic plant and the equipment used for EO extraction can establish the ratio of components in EO and also the quantity of undesirable impurities (pesticides).

Unfortunately the specifications provided by the diverse bodies that control and normalize the quality of EO, do not only serve technological aspects. They can, for example, indirectly influence the nature of an export-import policy of nation-states, thus limiting competitive access to home market EO into some countries [9].

Numerous volatile oils - mainly those of spices and herbs, but including those from Eucalyptus - have been used to extend the shelf-life of foods, beverages and pharmaceutical and cosmetic products; their antioxidant and antimicrobial activities have also pointed to a role in plant protection. Such a large diversity of applications, actual or potential, has meant that the antimicrobial properties of volatile oils and their constituents from a large number of plants have been assessed and reviewed [10].

Eucalyptus essential oil is extracted from Eucalyptus globulus of the Myrtaceae family and is also known as Tasmanian blue gum or blue gum. The Australian Blue-gum can sometimes reaches a height of 100 meters (300 feet), making it one of the highest trees in the world. There are over 500 species of Eucalyptus trees, with tough long and narrow bluegreen leaves, creamy white flowers and smooth pale bark [11].

Numerous varieties of the genus Eucalyptus from the Myrtaceae family are used in Algerian folk medicine for a range of therapy conditions. For instance, hot water extracts of dried leaves of Eucalyptus globulus are traditionally used as analgesic, anti-inflammatory, and antipyretic remedies for the symptoms of respiratory infections, such as cold, flue, and sinus congestion. Eucalyptus globulus essential oils (EGEO) are also widely used in modern cosmetics, food, and pharmaceutical industries [11]. In this regard, alcohols monoterpenoid components of the volatile compounds of the EGEO are commercially accessible for the management of the common cold and other symptoms of respiratory tract infections [12]. Phytochemical analysis has shown that the profile of the monoterpenoids varies among the Eucalyptus species, with potential variations in medicinal properties [13].

EGEO has been positioned under GRAS (Generally Regarded as Safe) class by Food and Drug Administration of USA and classified as non-toxic. Even the Council of Europe has accepted use of EGEO as a flavouring agent in foods $(<5 \mathrm{mg} / \mathrm{kg})$ and candies and confectionery items $(<15 \mathrm{mg} / \mathrm{kg})$ [11,14]. At small amounts, it is also used widely in detergents, soaps and perfumes. Presently, four to five thousand tonnes of Eucalyptus oil are 
traded every year in international markets and approximately $66 \%$ of this is extracted in Australia [11].

Given the changeability that can subsist for eucalyptus oils, even when they are distilled from the same botanical resource, there is evidently a need for some sort of standard or requirement for oils of commerce so that the buyer, or prospective buyer, knows what he can expect when he makes a purchase. The better commercial producers, mostly those which export their oil, frequently present their personal specifications and, if requested, these can be passed on by dealers or importers to their own customers.

For medicinal oils, 1,8-cineole (eucalyptol) content is important, while for perfumery oils the content of some particular ingredient such as citronellal and/or the overall fragrance characteristics are important [11].

The state Mitidja is rich in flora and report on the traditional herbal practices of Algeria highlighted the richness of the flora. Traditional practices based on herbs exist among various tribes in Northern Algeria [7,9]. Literature survey revealed that very little work has work has been carried out on Eucalyptus globulus plant growing in Algeria. It is consequently essential to explore the chemical composition of the EGEO and correlate the economic potential of the EO with the volatile oil constituents.

The objectives of this study were: $(i)$ the extraction of the essential oil from the leaves of Eucalyptus globulus Labill., Myrtaceae grown in Algeria, and the quantification of the yield thereof, (ii) the identification and quantification of the compounds in the essential oil obtained, and (iii) the determination of physical and chemical properties of EGEO.

\section{MATERIALS AND METHODS}

\section{1. Study area}

The latitude and longitude of Algeria is $28^{\circ} 00^{\prime} \mathrm{N}$ and $3^{\circ} 00^{\prime} \mathrm{E}$ respectively. It is located in northern Africa and lies between Morocco and Tunisia. The study area, Ain-Defla, is located about $80 \mathrm{~km}$ south-west of Algiers, the national capital. The climate is warm. In winter there is much more rainfall in Ain-Defla than in summer. The average annual temperature in Ain-Defla is $17.9^{\circ} \mathrm{C}$. About $791 \mathrm{~mm}$ of precipitation falls annually. The driest month is July with $2 \mathrm{~mm}$. Most precipitation falls in December, with an average of $130 \mathrm{~mm}$. The warmest month of the year is August with an average temperature of $26.9^{\circ} \mathrm{C}$. In January, the average temperature is $10.6^{\circ} \mathrm{C}$. It is the lowest average temperature of the whole year. The difference in precipitation between the driest month and the wettest month is $128 \mathrm{~mm}$. The average temperatures vary during the year by $16.3{ }^{\circ} \mathrm{C}$ (climate-data.org).

\section{2. Collection of herb material}

Leaves of Eucalyptus globulus Labill., Myrtaceae, were collected in the Eastern part of Ain-Defla (Hammam Righa city), in March 2012, from a single collection site. The leaves were air-dried in the shade at the ambient temperature, protected from the direct light, until further analysis. The identity of the plant specimen was confirmed at the Department of Botany of National Institute of Agronomy (Algiers, Algeria).

\section{3. Extraction of essential oil}

Eucalyptus essential oil was distilled from the aerial parts of the plants by steam distillation. The total quantity of fresh plant used varied from 600 to $700 \mathrm{Kg}$. The plant material was encumbered in the still and disposed in layers to allow suitable distribution of the steam. The process consists of passing water vapour at a low-pressure through a tank 
(called alembic) filled with aromatic plants. The steam obviously captures the volatile flavors that are enclosed in the plant, who then travel through a cold-water refrigerated serpentine and condense themselves into a liquid. The distillate will have a mix of water vapour and EO which return to their liquid form in the condensing recipient and are separated using a Florentine flask. Both the EO and the water called floral water or hydrosol is retained. The following Figure 1 summarises the process of Steam distillation.

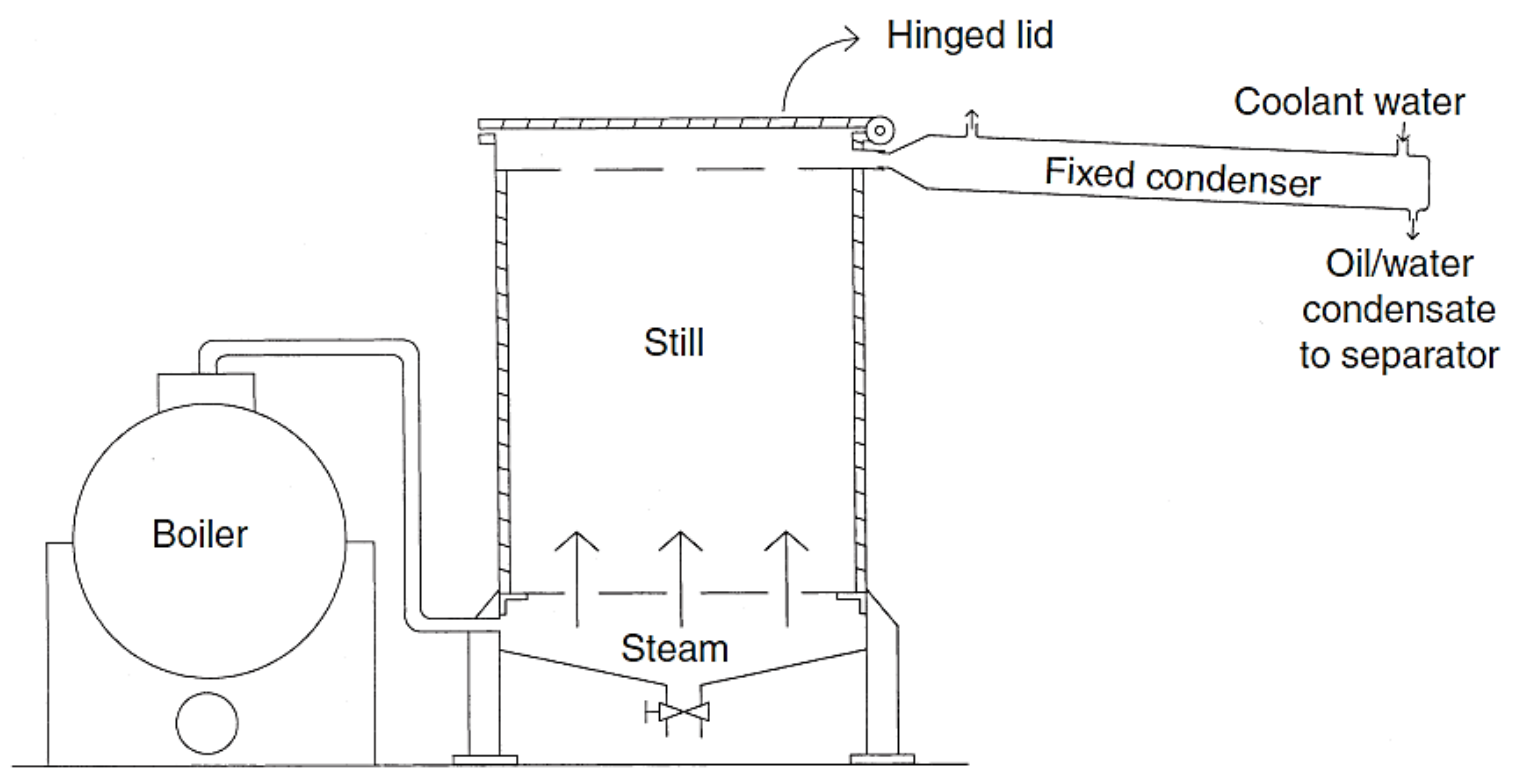

Figure 1. Steam distillation process with a separate boiler for extraction of Eucalyptus globulus essential oil [11].

The oils were dried over sodium sulphate and stored in clean brown glass bottles, and kept in a controlled temperature chamber, until the time of their analyses. The oil content in the Eucalyptus globulus was determined as percentage yield of oil which was calculated as the percent of the ratio of weight of oil to weight of Eucalyptus leaves.

\section{4. Analysis of Physicochemical properties}

Physicochemical properties are used to determine the quality of EGEO extracted. All the parameters were determined according to the method of European Pharmacopeia [15].

\section{4. 1. Specific gravity determination}

A tube of known weight (W) was filled first with essential oil and then with water and the respective weight $\mathrm{w} 1$ and $\mathrm{w} 2$ was determined. Then, the specific gravity was calculated using the following formula:

$$
d=\frac{\mathrm{w} 1-\mathrm{w}}{\mathrm{w} 2-\mathrm{w}}
$$




\section{4. 2. Determination of Refractive Index}

Refractive Index or index of refraction of a substance or medium is a measure of the speed of light in that medium expressed as speed of light in vacuum relative to that in the considered medium.

$$
n=\frac{\text { speed of light in a vacuum }}{\text { speed of light in medium }}
$$

The Refractive Index is used to distinguish water from other solvent and also to confirm the purity of EGEO. The Refractive Index of the Eucalyptus oil was measured by Abbe Refractometer using sodium D-line at $20^{\circ} \mathrm{C}$.

\section{4. 3. Determination of optical rotation and density}

The optical rotation of the EGEO was measured using Polarimeter (ADP 220 Polarimeter, Bellengham + Stanley Limited Model No. 36-220, England) with a 2 dm length polarimeter tube where the angle of rotation in degrees were read at $20{ }^{\circ} \mathrm{C}$ using D-line of polarized sodium light. The specific optical rotation was calculated following the procedure in the European Pharmacopoeia. Different concentrations of oil solutions (10, 5 and $2.5 \%)$ were prepared in methanol and the optical rotation was measured for the solutions of different concentrations.

\section{4. 4. Acid value determination}

Acid value is the mass of potassium hydroxide $(\mathrm{KOH})$ in $\mathrm{mg}$ that is requisite to neutralize one $g$ of chemical substance. The acid number is a measure of the amount of carboxylic acid groups in a chemical compound. The acid number is used to quantify the amount of acid present, in EGEO sample.

Acid value was determined according to the method of European Pharmacopeia. EGEO $(0.5 \mathrm{mg})$ was accurately weighted and dissolved in $10 \mathrm{ml}$ of $95 \%$ ethanol and 2-3 drops of phenolphthalein indicator was added. The free acid was then titrated with standard $0.1 \mathrm{~N}$ aqueous sodium hydroxide solution by adding the alkali drop-wise at a uniform rate of about 30 drops per minute. The content of the flask was continuously agitated. The primary manifestation of the red coloration that did not fade within 10 seconds was considered the end point. Afterward, the acid value was determined using the following equations:

$$
\text { Acide value }=\frac{5.61 \times(\text { number of } \mathrm{mL} \text { of } 0.1 \mathrm{~N} \mathrm{NaOH}))}{\text { Weight of sample in gram }}
$$

\section{4. 5. Saponification value determination}

Saponification value represents the number of milligrams of potassium hydroxide or sodium hydroxide required to saponify $1 \mathrm{~g}$ of EGEO under the condition specified. Saponification value was calculated by standard procedure. EGEO $(0.5 \mathrm{mg})$ was accurately weighed and dissolved in $10 \mathrm{ml}$ of ethanol and then $10 \mathrm{ml}$ of $2.5 \mathrm{~N} \mathrm{KOH}$ solution was added.

This procedure was performed together with blank experiment which was also performed omitting the oil. The mixture was refluxed for two hours then cooled. The unreacted $\mathrm{KOH}$ was titrated with standard $\mathrm{N} / 2$ oxalic acid by adding 2-3 drops of 
phenolphthalein indicator. After that, the saponification value was determined using the following equation:

$$
\text { Saponification value }=\frac{56 \times(\mathrm{V} 1-\mathrm{V} 2)}{2 \times \mathrm{W}}
$$

where, $\mathrm{W}$ is the weight of oil, V1 is the volume of $\mathrm{N} / 2$ oxalic acid for blank, V2 is the volume of $\mathrm{N} / 2$ oxalic acid for sample.

\section{4. 6. Iodine number determination}

Iodine number was determined according to the technique of European Pharmacopeia. EGEO $(0.25 \mathrm{mg})$ was dissolved in $10 \mathrm{ml}$ of chloroform. Then $25 \mathrm{ml}$ of iodobromide solution was added and allowed to stand for 30 minutes in dark. Again $30 \mathrm{ml}$ of $1 \mathrm{~N}$ potassium iodide and $100 \mathrm{ml}$ of distilled water were added and the liberated iodine was titrated with N/10 solution of sodium thiosulphate with constant shaking. When iodine color became quite pale, $1 \mathrm{ml}$ of $1 \%$ starch solution was added and the titration was continued until the blue color was discharged. A blank test was also carried out parallel under identical condition. The iodine number was determined using the formula:

$$
\text { Iodine number }=\frac{1.269(\mathrm{~V} 1-\mathrm{V} 2)}{\mathrm{W}}
$$

where, $\mathrm{W}$ is the weight of sample, $\mathrm{V} 1$ is the number of $\mathrm{ml}$ of thiosulphate consumed by the blank, $\mathrm{V} 2$ is the number of $\mathrm{ml}$ of thiosulphate consumed by the test sample.

\section{5. Chemical identification}

Determination of the chemical composition of the extracted EO from Eucalyptus globulus was carried out by Gas Chromatography-Mass Spectroscopy. Gas Chromatographic (GC) analysis were performed with a Hewlett Packard 6890 Series equipped with a HPChemstation data processor, fitted with a HP-5MS capillary column (30 m x $0.25 \mathrm{~mm}$ i.d., $0.25 \mu \mathrm{m}$ film thickness (Hewlett Packard, Palo Alto, USA); column temperature, $45{ }^{\circ} \mathrm{C}(8$ min) to $230{ }^{\circ} \mathrm{C}$ at $2{ }^{\circ} \mathrm{C} / \mathrm{min}, 180{ }^{\circ} \mathrm{C}, 230{ }^{\circ} \mathrm{C}(15 \mathrm{~min})$; injector temperature $250{ }^{\circ} \mathrm{C}$; detector temperature $250{ }^{\circ} \mathrm{C}$; split ratio 1:20; carrier gas $\mathrm{N}_{2}$. Volume injected $1 \mu \mathrm{L}$. The Gas Chromatography-Mass Spectrometry (GC-MS) analysis were performed in a HP $6890 \mathrm{GC}$ using a mass selective detector Hewlett Packard 6890/MSD5973, equipped with HP Chemstation software and Wiley 275 spectra data. A fused silica capillary column HP-5MS (30 m x $0.25 \mathrm{~mm}$ ), $0.25 \mu \mathrm{m}$ film thickness (Hewlett Packard, Palo Alto, USA) was used. The temperature program was the same used in the gas chromatography (GC) analysis: interface $280{ }^{\circ} \mathrm{C}$; split ratio 1:20; carrier gas $\mathrm{He}$; flow rate: $1.0 \mathrm{~mL} / \mathrm{min}$; ionization energy $70 \mathrm{eV}$; volume injected $1 \mu \mathrm{L}$.

The detected compounds were identified by processing the raw GC-MS data and comparing with National Institute of Standard and Technology (NIST, USA) mass spectral database and from retention times and mass spectra of standard compounds. Relative amounts of detected compounds were calculated based on GC peak areas. 


\section{RESULTS AND DISCUSSION}

\section{1. Yield of Eucalyptus essential oil}

The percentage yield of essential oil obtained from the steam distillation process of the fresh leaves of E. globules was $0.2 \%(\mathrm{w} / \mathrm{w})$. Our results are similar to those reported in the literature where the yield was $0.22 \%(\mathrm{w} / \mathrm{w}$, based on the fresh weight of the young leaves) with $E$. alba, but rather small compared to the results reported in the literature where the yield was $1.63 \%$ with $E$. citriodora [11].

The relative quantity $(\% \mathrm{w} / \mathrm{w})$ of EO from 10 selected Congolese Eucalyptus aromatic plant species presented in Table 1 varied from 0.2 to $1.9 \%$. The maximum value of EO was obtained for the fresh leaves of Eucalyptus globulus and E. citriodora (1.87 and $1.63 \%$, respectively) while the lowest was for the fresh leaves of E. robusta and E. deglupta ( 0.13 and $0.15 \%$, respectively) [16].

Table 1. Essential oil (EO) yields of different Eucalyptus spices from fresh plant material.

\begin{tabular}{|c|c|}
\hline Botanical names & EO (\%) \\
\hline Eucalyptus alba Reinw. Ex Blume NL12891 (Myrtaceae) & 0.22 \\
\hline Eucalyptus camadulensis Dehnh. NL 03901 (Myrtaceae) & 0.30 \\
\hline Eucalyptus citriodora Hook. NL03902 (Myrtaceae) & 1.63 \\
\hline Eucalyptus deglupta Gerald D. Carr NL 12892 (Myrtaceae) & 0.15 \\
\hline Eucalyptus globules Labill. c. NL 12893 (Myrtaceae) & 1.87 \\
\hline Eucalyptus propinqua Deane and Maiden NL 12894 (Myrtaceae) & 0.65 \\
\hline Eucalyptus saligna R. Baker NL 03903 (Mytaceae) & 0.78 \\
\hline Eucalyptus terticornis Sm. NL 12895 (Myrtaceae) & 0.45 \\
\hline Eucalyptus urophylla S.T. Blake NL 12896 (Myrtaceae) & 0.53 \\
\hline Eucalyptus robusta Smith NL 02891 (Myrtaceae) & 0.13 \\
\hline
\end{tabular}

Further, yields of different Eucalyptus EO from fresh plant materials of some selected Congolese trees varied significantly from one species to another. Disparity with these yields compared to those formerly reported in the literature for the Eucalyptus aromatic plants collected in other geographic areas in the world could be linked to several factors such as climate, nature of the sol, time of collection, mode of extraction and the age of the tree $[11,17]$.

\section{2. Physical and chemical properties of essential oil}

Physicochemical properties are useful methods in determining the quality of essential oils [9]. Quality assessment of EO requires different analysis some of which are sensory evaluation. The sensory evaluation of the EGEO was assessed by the panel of students in the Department of Biology (University of Blida, Algeria). The volatile leaf oil extracted from 
Algerian Eucalyptus globulus trees by steam distillation were of light yellow color having camphor like smell, agreeable with findings of Iqbal et al. [18]. The physicochemical properties of the EGEO were evaluated using the standard procedure and the results are presented in Table 2.

Table 2. Physical and chemical properties of Eucalyptus globulus essential oil obtained by steam distillation.

\begin{tabular}{|c|c|c|c|}
\hline & Parameters & Results & AFNOR [14]* \\
\hline \multirow{4}{*}{ Physical properties } & Refractive index $\left(20^{\circ} \mathrm{C}\right)$ & $1,46933 \pm 0,00057$ & 1.4590 to 1.4670 \\
\hline & Specific gravity $\left(20^{\circ} \mathrm{C}\right)$ & 0.919 & 0.906 to 0.923 \\
\hline & optical rotation $\left(20^{\circ} \mathrm{C}\right)$ & +1.5956 & $0^{\circ}$ to $+10^{\circ}$ \\
\hline & $\mathrm{pH}\left(22^{\circ} \mathrm{C}\right)$ & 4.9 & - \\
\hline \multirow{4}{*}{$\begin{array}{l}\text { Chemical } \\
\text { properties }\end{array}$} & Acide value & 0.5945 & $<10$ \\
\hline & Saponification value & 19.576 & - \\
\hline & Hydroxyle value & 31.61 & 10 to 100 \\
\hline & Iodine value & 41.52 & $20-60$ \\
\hline
\end{tabular}

Taking the data for these properties, Algerian Eucalyptus oil showed a mean refractive index of 1.46933, an average optical rotation of $+1.5956^{\circ}$ and an average specific gravity of $0.919 \mathrm{~g} / \mathrm{cm}^{3}$. In relation to samples from other world zones, Algerian oils were closer to those from Pakistan and Ethiopia [13,18,19]. All the chemical properties of volatile oil were in the range indicated by the AFNOR standards for Eucalyptus globulus.

These results are a preliminary contribution to the establishment of standard and average values of chemical and physical parameters for a regional product of importance to industry. The stability and constancy of Eucalyptus chemical composition and characteristics over a number of years is also relevant for its marketable utilization, as it is the basis of a consistent product.

\section{3. Chemical composition of essential oil}

Determination of the chemical composition of the extracted EO from Eucalyptus globulus was carried out by Gas Chromatography-Mass Spectroscopy. It is well-known that Eucalyptus plants produce terpenoidal hydrocarbons and EO which can be grouped as medicinal, industrial and perfumery types depending on their chemical composition.

The GC/MS total ion chromatogram of the EGEO was obtained under the conditions described above, and the obtained results are seen in Table 3.

GC-MS analyses revealed the presence of 14 compounds representing $90.98 \%$ of the total oil. The major component was 1,8-cineole $(51.08 \%)$ followed by $\alpha$-pinene $(24.6 \%)$, while L-pinocarveol (9.98\%) and globulol (2.81) were minor main components (Table 4). Other compounds identified in the oil obtained were $\alpha$-terpineol, myrtenol, camphene and ciscarveol. The Eucalyptus oil consisted mostly of oxygenated monoterpenes. 
1,8-cineole determines the business value of the oil and its significance as a raw material for diverse industries. Different percentages of 1,8-cineole in E. globules leaf oil have been mentioned: $64.5 \%$ in Uruguay, $77 \%$ in Cuba, $86.7 \%$ in California, $58 \%$ to $82 \%$ in Morocco, $48.7 \%$ in Africa, and $50 \%$ to $65 \%$ in Argentina [20].

The majority volatile oil extracted from E. globulus contains at least $5 \%$ to as high as $95 \%$ 1,8-cineole, a typical constituent found in most Oleum Eucalypti. Geographical and climatic conditions have been implicated as factors responsible for these variations. Other factors may include time of harvest, age of plant and method of distillation. Although steam and hydro-distillations are the most famous method for extraction, demerit of this technique includes modification of components by auto-oxidation during distillation.

Table 3. Chemical composition of essential oil from Eucalyptus globulus extracted by steam distillation.

\begin{tabular}{|c|c|c|c|}
\hline $\mathbf{N}^{\circ}$ & $\begin{array}{c}\text { Retention Time } \\
(\mathbf{m n})\end{array}$ & Compounds & $\mathbf{\%}$ \\
\hline 1 & 13.117 & $\alpha$-Pinene & 24.600 \\
\hline 2 & 13.517 & Camphene & 0.117 \\
\hline 3 & 14.460 & $\beta$-Pinene & 0.217 \\
\hline 4 & 16.323 & $\mathbf{1 , 8}$-cineol & $\mathbf{5 1 . 0 8 3}$ \\
\hline 5 & 17.083 & $\alpha$-Campholenal & 0.390 \\
\hline 6 & 18.729 & Fenchol & 0.179 \\
\hline 7 & 19.587 & L-pinocarveol & 9.987 \\
\hline 8 & 20.233 & Borneol & 0.346 \\
\hline 9 & 20.541 & 4 -Terpineol & 0.178 \\
\hline 10 & 20.781 & Caren-4-ol & 0.195 \\
\hline 11 & 20.907 & $\alpha$-Terpineol & 0.486 \\
\hline 12 & 21.044 & Myrtenol & 0.202 \\
\hline 13 & 21.850 & Cis-Carveol & 0.187 \\
\hline 14 & 30.509 & Globulol & 2.817 \\
\hline & & & $\mathbf{9 0 . 9 8 4}$ \\
\hline
\end{tabular}

Our findings are similar to those from Tsiri et al. [21] and Cimanga et al. [16], who revealed that the major components of Eucalyptus oils was 1,8-cineole. The chemical profiles of a variety of other Eucalyptus species have been published [22,23], and are comparable to our results. Nevertheless, Singh et al. (22) extracted the leaf oil of E. urophylla from India, with $p$-cymene $(75.0 \%), \alpha$-pinene $(7.0 \%)$, and $\alpha$-terpinene $(4.0 \%)$ being the main compounds. We suggest that such divergence might also be linked to the differences in the chemo type of the trees.

The percentage composition of components of various Eucalyptus oils from fresh plant materials of some selected trees are given in Table $\mathbf{5}$ and varied significantly from one species to another. 
Table 4. Major components obtained in the Eucalyptus globulus essential oil.

\begin{tabular}{|c|c|c|c|}
\hline Name & 1,8-cineol & $\alpha$-pinene & L-pinocarveol \\
\hline & $\mathrm{CH}_{3}$ & $\mathrm{CH}_{3}$ & \\
\hline Synonyms & $\begin{array}{c}\text { Eucalyptol } \\
\text { 1,8-epoxy-p-menthane } \\
\text { Cajeputol }\end{array}$ & $\begin{array}{c}\alpha \text {-pinene oxide } \\
(1 R, 5 R) \text {-2-Pinene }\end{array}$ & 10-Pinen-3-ol \\
\hline Formula & $\mathrm{C}_{10} \mathrm{H}_{18} \mathrm{O}$ & $\mathrm{C}_{10} \mathrm{H}_{16}$ & $\mathrm{C}_{10} \mathrm{H}_{16} \mathrm{O}$ \\
\hline $\begin{array}{c}\text { Average Mass } \\
(\mathrm{g} / \mathrm{mol})\end{array}$ & 154.24 & 136.23 & 152.23 \\
\hline Roles & $\begin{array}{c}\text { Flavouring agent } \\
\text { A food additive that is } \\
\text { used to added improve } \\
\text { the taste or odour of a } \\
\text { food. }\end{array}$ & Plant metabolite & Plant metabolite \\
\hline
\end{tabular}

Table 5. Percentage composition of the essential oils extracted from 8 Eucalyptus plant species $[11,16]$.

\begin{tabular}{|c|c|c|c|c|c|c|c|c|}
\hline Compound & $\begin{array}{c}E . \\
\text { alba }\end{array}$ & $\begin{array}{c}E . \\
\text { camadulensis }\end{array}$ & $\begin{array}{c}E . \\
\text { citriodora }\end{array}$ & $\begin{array}{c}E . \\
\text { deglupta }\end{array}$ & $\begin{array}{c}E . \\
\text { urophylla }\end{array}$ & $\begin{array}{c}E . \\
\text { globulus }\end{array}$ & $\begin{array}{c}E . \\
\text { propinqua }\end{array}$ & $\begin{array}{c}E . \\
\text { saligna }\end{array}$ \\
\hline$\alpha$-Thuyene & - & 0.6 & - & 0.3 & 0.2 & - & - & - \\
\hline$\alpha$-Pinene & 4.3 & 5.4 & 2.3 & 1.2 & 10.1 & 9.3 & 20.3 & 5.6 \\
\hline Camphene & - & 1.6 & 0.3 & - & 0.3 & 23.1 & 0.6 & 0.3 \\
\hline$\beta$-Pinene & $\mathbf{2 5 . 3}$ & 0.1 & 1.7 & 0.7 & 2.1 & 2.7 & 9.3 & - \\
\hline Myrcene & - & 0.2 & 0.6 & 0.3 & 0.4 & - & 1.2 & 1.7 \\
\hline Limonene & 4.6 & 5.4 & - & 2.6 & 6.4 & 5.1 & 3.2 & 10.1 \\
\hline 1,8 -Cineole & 5.2 & $\mathbf{5 8 . 9}$ & 1.2 & $\mathbf{3 5 . 7}$ & $\mathbf{5 7 . 7}$ & $\mathbf{4 4 . 3}$ & $\mathbf{3 2 . 4}$ & $\mathbf{6 1 . 3}$ \\
\hline$\alpha$-Phellandrene & - & - & - & 7.2 & 1.2 & - & - & 2.3 \\
\hline$\beta$-Ocimene & - & - & - & 0.1 & 4.4 & - & 3.7 & - \\
\hline$\gamma$-Terpinene & 1.2 & 2.8 & 0.3 & 2.8 & 0.2 & - & 0.6 & - \\
\hline
\end{tabular}




\begin{tabular}{|c|c|c|c|c|c|c|c|c|}
\hline$p$-Cymene & 7.4 & 2.1 & - & - & - & 1.6 & 6.3 & 7.2 \\
\hline $\begin{array}{l}\text { cis-Linalool } \\
\text { oxide }\end{array}$ & - & - & 1.3 & - & - & - & - & - \\
\hline Citronellal & - & - & 72.7 & - & - & - & - & - \\
\hline Linalool & 0.4 & - & 0.1 & - & 2.5 & 0.3 & 0.2 & - \\
\hline Isopugegol & 3.7 & - & - & - & 0.4 & - & - & - \\
\hline$\beta$-Caryophyllene & 4.3 & - & 2.6 & 0.2 & - & - & 2.2 & - \\
\hline Aromandendrene & 1.7 & 2.1 & - & 1.3 & - & 1.3 & 0.3 & - \\
\hline$\beta$-Terpineol & 13.6 & - & - & 6.3 & - & - & - & - \\
\hline Terpin-4-ol & 1.7 & - & - & 1.2 & - & 0.2 & 0.8 & - \\
\hline Myrtenal & 0.2 & 3.5 & - & - & - & - & - & - \\
\hline$\alpha$-Humulene & 2.3 & - & - & - & - & - & - & - \\
\hline Cryptone & - & 1.1 & - & 25.4 & 0.4 & 1.3 & - & 3.7 \\
\hline$\alpha$-Terpineol & 6.2 & 2.7 & 0.7 & 1.4 & 1.3 & 0.3 & 7.4 & 3.1 \\
\hline Borneol & - & 1.3 & - & - & 0.4 & - & - & 2.1 \\
\hline $\begin{array}{c}\alpha \text {-Terpenyl } \\
\text { acetate }\end{array}$ & - & 2.1 & 1.5 & - & - & 1.2 & 3.1 & - \\
\hline Geranial & 0.1 & - & - & - & 0.3 & - & - & - \\
\hline Carvacrol & - & 0.1 & - & 1.3 & 0.2 & - & - & - \\
\hline Cuminaldehyde & - & 1.3 & - & - & - & - & - & - \\
\hline Citronellol & 2.3 & - & 6.3 & - & - & 0.1 & 1.6 & - \\
\hline Myrtenol & - & 4.3 & - & 7.4 & 0.1 & - & - & - \\
\hline Nerol & - & - & - & - & - & - & - & - \\
\hline Geraniol & - & 2.1 & - & - & - & 0.2 & - & - \\
\hline $\begin{array}{c}\text { Citronellyl } \\
\text { acetate }\end{array}$ & - & - & 2.3 & 0.2 & - & - & - & - \\
\hline Geranyl acetate & - & - & - & - & - & - & - & - \\
\hline Globulol & 2.4 & 1.6 & - & 3.1 & 4.4 & 7.3 & 2.6 & 0.3 \\
\hline Spathulenol & 4.1 & - & - & 0.2 & - & - & - & - \\
\hline Eugenol & - & - & 3.5 & - & - & - & - & - \\
\hline Methyleugenol & - & - & 0.6 & - & - & - & - & - \\
\hline$\alpha$-Eudesmol & 2.7 & - & - & - & - & - & - & - \\
\hline$\beta$-Eudesmol & 4.6 & - & - & - & - & - & - & - \\
\hline
\end{tabular}

a) -: not identified (trace or $\%<0.1$ ); Compounds listed in elution according to their retention indices.

These results show that the volatile oil of each tree species has a particular quantitative and qualitative chemical composition. Components such as 1,8-cineole, $\alpha$ and $\beta$-pinene, $p$ cymene and citronellal were found to be the dominant. Constituents listed in Table 5 were also determined in diverse amounts in the similar tree species collected in other region of the world $[11,13,18]$. 


\section{CONCLUSIONS}

Based on our findings, we conclude that steam distillation represents a valuable option to traditional hydrodistillation for the efficient extraction of volatile oil from Eucalyptus globulus. Meanwhile, the aromatic oil extracted by steam distillation could be considered as a natural flavouring agent in food processing.

In conclusion, based on the chemical profile and physicochemical parameters, the quality of Eucalyptus globulus EO from Algeria are close to the oil produced in other parts of the world. The minor differences in the composition of the oil may arise due to the difference in chemotypes, environmental factors and condition of growth. Moreover, our results are a preliminary contribution to the establishment of standard values of chemical profile and physicochemical parameters for a regional product of interest to industry.

\section{References}

[1] E. Edris, Phytotherapy Research 21(4) (2007) 308-323.

[2] F. Bakkali, S. Averbeck, M. Idaomar, Food and Chemical Toxicology 46(2) (2008) 446475 .

[3] Abadi, A. Hassani, International Letters of Chemistry, Physics and Astronomy 9 (2013) 17-24.

[4] M. N. Boukhatem, A. Kameli, F. Saidi, Food Control 34(1) (2013) 208-213.

[5] M. N. Boukhatem, A. Kameli, M. A, Ferhat, F. Saidi, M. Mekarnia, Libyan Journal of Medicine 8(1) (2013).

[6] M. H., Mohammed, M. A, Ibrahim, S. E. Elsheikh, International Letters of Chemistry, Physics and Astronomy 9 (2013) 25-30.

[7] M. N. Boukhatem, A. Kameli, M. A. Ferhat, F. Saidi, K. Tayebi, Journal für Verbraucherschutz und Lebensmittelsicherheit 9(1) (2014) 13-21.

[8] Z. Djaafar, O. M. Ridha, International Letters of Chemistry, Physics and Astronomy 1 (2014) 25-30.

[9] M. N. Boukhatem, M. S. Hamaidi, F. Saidi, Y. Hakim, Nature \& Technologies 3 (2010) $37-45$.

[10] D. R. Batish, H. P. Singh, S. Kaur, Forest Ecology and Management 256(12) (2008) 2166-2174.

[11] J. J. Coppen, CRC Press (2003) 112-145.

[12] Cermelli A. Fabio, G. Fabio, P. Quaglio, Current microbiology 56(1) (2008) 89-92.

[13] M. Ashraf, Q. Ali, F. Anwar, A. I. Hussain, Asian Journal of Chemistry 22(3) (2010) 1779-1786.

[14] AFNOR (2000) Association Française de Normalisation.

[15] European Pharmacopoeia Commission, (2001) Council of Europe. 
[16] K. Cimanga, K. Kambu, L. Tona, A. J. Vlietinck, Journal of Ethnopharmacology 79(2) (2002) 213-220.

[17] S. Zrira, J. M. Bessiere, B. Benjilali, Flavour and Fragrance Journal 19(2) (2004) 172175.

[18] Z. Iqbal, I. Hussain, A. Hussain, M. Y. Ashraf, Pakistan Journal of Botany 35((2004) 843-852.

[19] P. A. Subramanian, K. Nigussie, Journal of Pharmaceutical and Biomedical Sciences 17(17) (2012).

[20] I. Viturro, A. C. Molina, C. I. Heit, Journal of Essential Oil Research 15(3) (2003) 206208.

[21] Tsiri O. Kretsi, C. G. Spyropoulos, Flavour and Fragrance Journal 18(3) (2003) 244247.

[22] K. Singh, J. J. Brophy, K. C. Gupta, Indian Perfumer 32 (1988) 201-204.

[23] L. G. Batista-Pereira, J. B. Fernandes, P. C. Vieira, Journal of the Brazilian Chemical Society 17(3) (2006) 555-561. 